\title{
Cyclic activity changes during extinction in rats: A potential model of depression*
}

\author{
ERIC KLINGER †, STEVEN G. BARTA, and ERNEST D. KEMBLE \\ University of Minnesota, Morris, Minnesota 56267
}

\begin{abstract}
Rats' open-field activity immediately following extinction trials in a runway rose sharply from baseline, then dropped below baseline, and finally recovered. There was no discernible relationship between activity levels and runway performance during acquisition or extinction. The data confirm a theory that a sequence of invigoration, depression, and recovery of noninstrumental locomotor activity (an "incentive-disengagement cycle") may regularly accompany incentive loss, including experimental extinction.
\end{abstract}

The experiment reported here, which describes cyclic changes in noninstrumental activity during extinction, grew out of a theory concerning the consequences of incentive losses in humans (Klinger, in press). Briefly, this theory suggests that behavioral extinction is characterized by an initial response invigoration, followed by depression, and finally ending in recovery (an "incentive-disengagement cycle"). Since the initial ("response invigoration" or frustration effect) portion of the proposed cycle has been extensively documented in animals (e.g., Amsel, 1958, 1962) and has proved to be quite robust, it seemed of considerable interest to explore the hypothesized sequelae to the frustration effect ("depression" and "recovery") in animals as well.

In order to avoid confounding general depression of response with the specific reduction of operant responses during extinction, it was necessary to find a response on which specific reward had not earlier been contingent. Open-field activity levels following runway trials, which had previously been shown to rise after unrewarded trials (Gallup \& Altomari, 1969), seemed to fit this specification. The hypotheses, then, were that during the extinction of a runway response, postrunway activity levels would first rise above their acquisition-period baseline during early extinction trials, then drop below baseline later in extinction, and finally recover to the previous baseline (except for losses attributable to adaptation in the open field). The trend of activity levels over trials was thus predicted to show a strong cubic orthogonal component.

\section{METHOD}

\section{Subjects}

Ss were 40 experimentally naive male hooded rats (Simonsen Laboratories), initially weighing from 300 to $360 \mathrm{~g}$. One S (who

*This research was supported by a grant from the University of Minnesota Graduate School. We thank Nancy R oberts for her technical assistance.

$\dagger R$ equests for reprints should be sent to Eric Kling er, Division of Social Sciences, University of Minnesota, Morris, Minnesota 56267 . had been assigned to the control group) failed to run in the runway and was discarded.

\section{Apparatus}

A Hunter Model 380 straight runway $(10 \times 10 \times 76 \mathrm{~cm})$ provided the operant response to be extinguished in the experimental groups. Running latencies were measured from the startbox door to a photocell relay $76 \mathrm{~mm}$ from the goalbox door. Activity levels following runway trials were observed in an activity box, $81 \times 81 \times 41 \mathrm{~cm}$, painted flat-black and divided by thin white lines into $10-\mathrm{cm}$ squares.

\section{Procedure}

Ss were assigned randomly to five groups matched for body weight. For 5 days, all Ss received $5 \mathrm{~min} /$ day of preliminary prehandling and runway familiarization, while body weight was reduced to $85 \%( \pm 2 \%)$ of ad lib value by restricting food intake. They remained individually housed and had free access to water throughout the experiment. Not sooner than $15 \mathrm{~min}$ after each day's testing, they received a ration of food adjusted to maintain weight at $85 \%$ of ad lib weight.

After the prehandling period, all Ss received 48 acquisition trials for food reward (five 45-mg Noyes food pellets), after which Groups 1 to 4 received 16 nonrewarded extinction trials and Control Group 5 received 16 further rewarded trials. Four runway trials were scheduled daily with intertrial intervals not less than $50 \mathrm{~min}$, except that on the fourth and fifth days of extinction there were only two runway trials per day.

Activity levels were indexed (following Gallup \& Altomari, 1969) by the number of activity-box squares entered during 60 -sec activity trials. Each $S$ was placed into the activity box individually immediately after consuming food reward in one runway acquisition trial and immediately after nonreward 1 in four extinction trials (or four correspond ing additional rewarded trials in the case of the controls). In both reward and nonreward trials, Ss spent about $5 \mathrm{sec}$ in the goalbox. The number of activity trials per $S$ was held down to five (henceforth referred to as Activity Trials 1 to 5) in order to reduce adaptation effects. Since it was desirable to assess the effects of runway conditions on activity levels at all stages of acquisition and extinction, different experimental groups were assigned to be activity-tested following different sets of runway trials (Table 1).

\section{RESULTS}

All groups readily acquired the runway response and performed rapidly and stably by the 48 th training trial. Group latencies differed by no more than $0.45 \mathrm{sec}$ 
Table 1

Identity of Runway Trials Followed by Activity Trials

\begin{tabular}{ccc}
\hline & \multicolumn{2}{c}{ Runway Trials } \\
\cline { 2 - 3 } Groups & Acquisition & Extinction \\
\hline 1 & 12 & $1,5,9,13$ \\
2,5 & 24 & $2,6,10,14$ \\
3 & 36 & $3,7,11,15$ \\
4 & 48 & $4,8,12,16$ \\
\hline
\end{tabular}

during the last 4 days of training. Analysis of variance revealed a highly significant decline in latencies during training ( $F=9.53, \mathrm{df}=11 / 374, \mathrm{p}<.005$ ), but there was no suggestion of either group differences $(F=0.53$, $\mathrm{df}=4 / 34)$ or a Group by Days interaction $(F=1.21$, df $=44 / 374)$. During extinction, the latencies of Groups 1 to 4 (nonrewarded) increased steadily $(\mathrm{F}=23.41$, $\mathrm{df}=3 / 84, p<.001)$. There were, however, no group differences $(F=1.27, \mathrm{df}=3 / 28)$ and no Groups by Days interaction $(F=1.40, \mathrm{df}=9 / 84)$. The latencies of the rewarded control group, which continued to run rapidly during this phase of the experiment, were well within the range of Groups 1 to 4 on Trial 1 of extinction $(U=109)$ but were significantly lower by the final extinction trial $(\mathrm{U}=16, \mathrm{~N}=7 / 32, \mathrm{p}<.02)$.

During the extinction of their runway responses, the postrunway activity levels of Groups 1 to 4 (analyzed by extended trend analysis of variance) showed the predicted rise, fall, and recovery (Fig. 1), with a strong cubic orthogonal component of the trend for these four groups combined ( $p<.001$ ), accounting for $9.3 \%$ of the total variance and $54.0 \%$ of the trials main effect. There much weaker but still significant linear $(p<.025)$ quadratic $(p<.005)$ and quartic $(p<.01)$ orthogonal components. Taking each experimental group separately, the cubic trends were significant $(p<.01)$ in all but Group 1, which produced a significant $(p<.005)$ quartic trend. $^{2}$ The activity levels of Control Group 5 failed to show any systematic change over trials. The Groups by Trials interaction (comparing the four combined experimental groups with the control group) contained a significant cubic component $(p<.025)$.

Combining the activity scores for the four experimental groups, the means for Activity Trials 1 to 5 are, respectively, $45.3,52.3,51.8,40.9$, and 45.5 , with a within-groups Ss by Trials interaction mean square of 50.5. Applying Duncan's multiple-range test, the Activity Trial 2 and 3 means are significantly greater than all others and the Activity Trial 4 mean is significantly lower than all others $(p<.05)$. Thus, the Trial 4 activity level is depressed below both the acquisition level and the level eventually reattained on Activity Trial 5.

Comparing the experimental groups with the control group, the experimental groups' activity level is also higher than the controls' on Activity Trial $2(p<.05)$ and lower than the controls' on Activity Trial 4 $(p<.05)$. Thus, comparisons within the trials of the experimental groups, as well as comparisons between the experimental and control groups, confirm the invigoration, depression, and recovery phases of the hypothetical incentive-disengagement cycle.

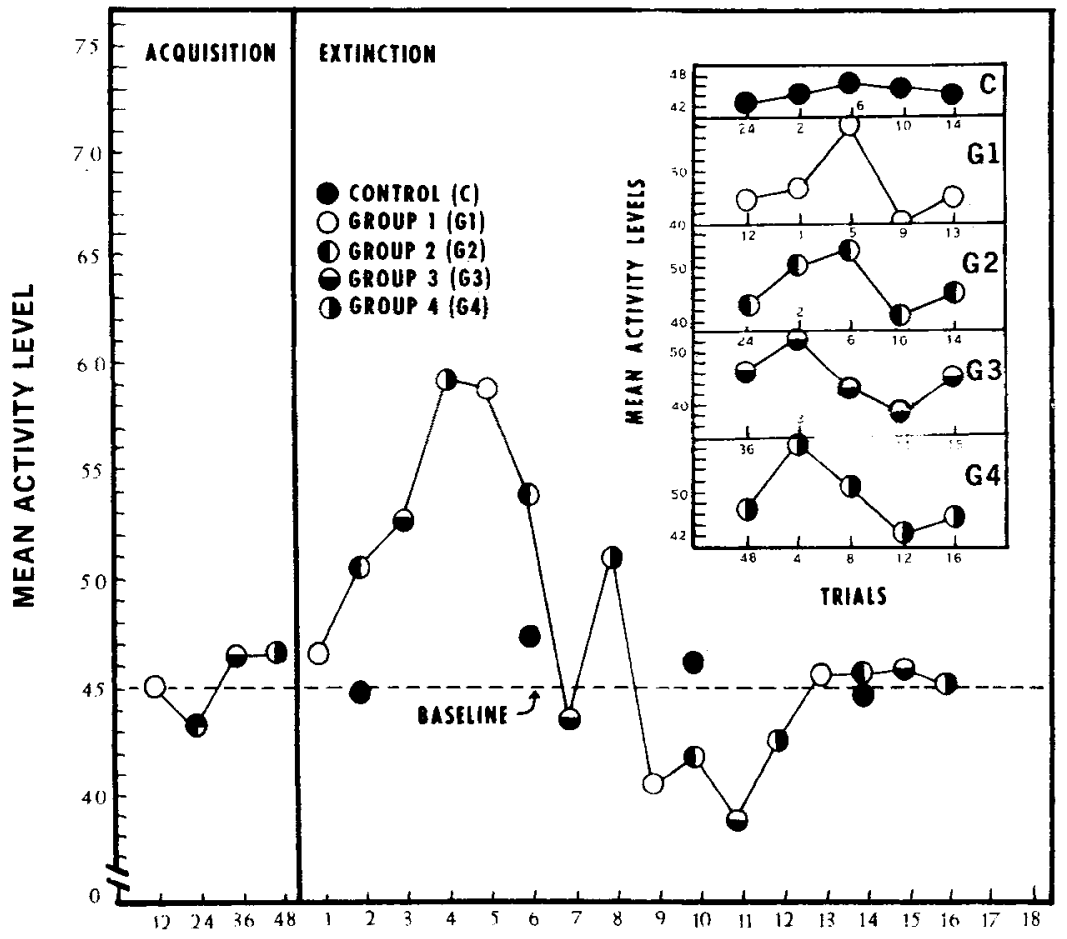

Fig. 1. Activity levels (number of $10-\mathrm{cm}$ squares entered per $60 \mathrm{sec}$ ) as a function of preceding runway trials. The large curve is a composite of data from four experimental groups, and their separate curves are presented upper right. The unconnected black dots represent the activity levels of Control Group 5, also presented extreme upper right. The second point from the left, in the large curve, represents identical activity means for Groups 2 and 5 (control). 


\section{DISCUSSION}

Several considerations argue against the possibility that the activity measures reflected altered runway performance in any direct way. First of all, the activity levels of all groups remained stable during acquisition, while runway latencies were declining markedly toward asymptotic values. In addition, the runway latencies of all groups showed no appreciable increase on the second extinction trial, while activity scores showed a reliable increase. Finally, during the extinction trials in which activity increased and then declined (Extinction Trials 2 to 13), runway latencies increased linearly with no suggestion of cyclic changes. It seems clear, then, that the present activity data do not reflect in any direct and obvious way the instrumental responses that preceded them. It cannot be denied, however, that similarities in the two response measures may have contributed in some subtle way to these results. It would be of great interest to see whether similar cyclic changes in activity were demonstrable during the extinction of instrumental responses (e.g., barpressing) which did not bear a close resemblance to the activity measures.

Apart from their general implications for theories of depression, the results bear directly and specifically on two theoretical issues that have been raised recently, one with respect to the frustration effect (Amsel, 1958; Staddon, 1972) and the other with respect to a learned-helplessness interpretation of reactive depression (Seligman, 1974).

Staddon proposed to reinterpret Amsel's frustration effect as the result of reward and reward-related cues briefly inhibiting the response class that is instrumental for obtaining them, rather than nonreward energizing subsequent response. Actually, however, it is unclear how either Staddon's interpretation or Amsel's original drive-enhancement explanation of the frustration effect accounts for the continued rise in activity levels through the first four trials of runway extinction. In the case of Staddon's formulation, there is no reason to suppose that absence of reward on the second extinction trial should disinhibit response more effectively than on the first, unless one were to argue that the goalbox itself exerts inhibitory effects through association with reward and that its inhibitory effect diminishes progressively during extinction. However, it is difficult to see how such a process would produce the depression of activity noted on Trials 9 to 12 of runway extinction. Moreover, it is not clear that Staddon's formulation would extend to a response (open-field activity) so unlike the extinguished operant (runway running).

Amsel's (1958) assumption that frustrative nonreward increases drive levels would account for the increased vigor of open-field activity immediately following nonreward. Since this drive effect may be assumed to have dissipated during the (at least) 50-min intertrial interval, however, it is not clear why activity levels should steadily rise during the first four runway extinction trials. It is also not clear how this position would account for the depressed activity noted on Extinction Trials 9 to 12 .

Seligman's theory of reactive depression as learned helplessness stems from observations (Overmier \& Seligman, 1967; Seligman \& Groves, 1970; Seligman \& Maier, 1967) that organisms learn to escape stressful conditions such as electric shock with much more difficulty if they have first been subjected to inescapable stress in another setting. The theory attributes their reduced instrumental activity to their having learned that they are helpless. Two features of the present data seem hard to explain with a learned-helplessness interpretation. First, the depressed activity responses in this study do not seem even remotely instrumentally related to the extinguished runway response. Learned helplessness would therefore have to generalize rather widely to account for these data. Second, the activity levels recovered from their depression even while the animals continued to experience nonreward in the runway and while running latencies continued to rise. This finding seems to contradict a simple learning interpretation of the depressed activity phase.

It is not automatically apparent that, taken by themselves, rats' depressed activity levels during extinction have much in common with human depression. However, the fact that this nonobvious phenomenon could be predicted on the basis of a conceptualization derived from data on depression in humans and lower primates generates some confidence that the one may be a homologue of the other. Insofar as this proves to be true, the discovery of a depression-like process in rats may provide a valuable tool for the investigation of variables which instigate, modify, or abolish depressive processes, including situational, learning-history, genetic, neurological, and pharmacological variables.

\section{REFERENCES}

Amsel, A. The role of frustrative nonreward in noncontinuous reward situations. Psychological Bulletin, 1958, 55, 102-119.

Amsel, A. Frustrative nonreward in partial reinforcement and discrimination learning: Some recent history and a theoretical extension. Psychological R eview, 1962, 69, 306-328.

Gallup, G. G., Jr., \& Altomari, T. S. Activity as a postsituation measure of frustrative nonreward. Journal of Comparative \& Physiological Psychology, 1969, 68, 382-384.

Klinger, $\mathrm{E}$. Consequences of commitment to and disengagement from incentives. Psychological R eview, in press.

Overmier, J. B., \& Seligman, M. E. P. Effects of inescapable shock upon subsequent escape and avoidance responding. Journal of Comparative \& Physiological Psychology, 1967, 63, 28-33.

Seligman, M. E. P. Depression and learned helplessness. In R. J Friedman and M. M. Katz (Eds.), The psychology of depression: Contemporary theory and research. New York: Halstead/Wiley, 1974.

Seligman, M. E. P., \& Groves, D. P. Nontransient learned helplessness. Psychonomic Science, 1970, 19, 191-192.

Seligman, M. E. P., \& Maier, S. F. Failure to escape traumatic shock. Journal of Experim ental Psychology, 1967, 74, 1-9.

Staddon, J. E. R. R einforcement omission on temporal go-no-go schedules. Journal of the Experimental A nalysis of Behavior, 1972, 18, 223-229. 


\section{NOTES}

1. On the runway trial before their final activity tests, two Ss (one from each of Groups 2 and 4) failed to traverse the runway within 60 sec and were thereupon placed directly from the runway startbox into the activity box. Their activity scores were well within their groups' range on that trial.
2. The following other components of trend reached significance in analyses of individual groups: in Group 2, quadratic $(p<.001)$ and quartic $(p<.005)$; in Group 4 , linear $(p<.01)$ and quadratic $(p<.025)$.

(R eceived for publication April 30, 1974; accepted July 16, 1974.) 